
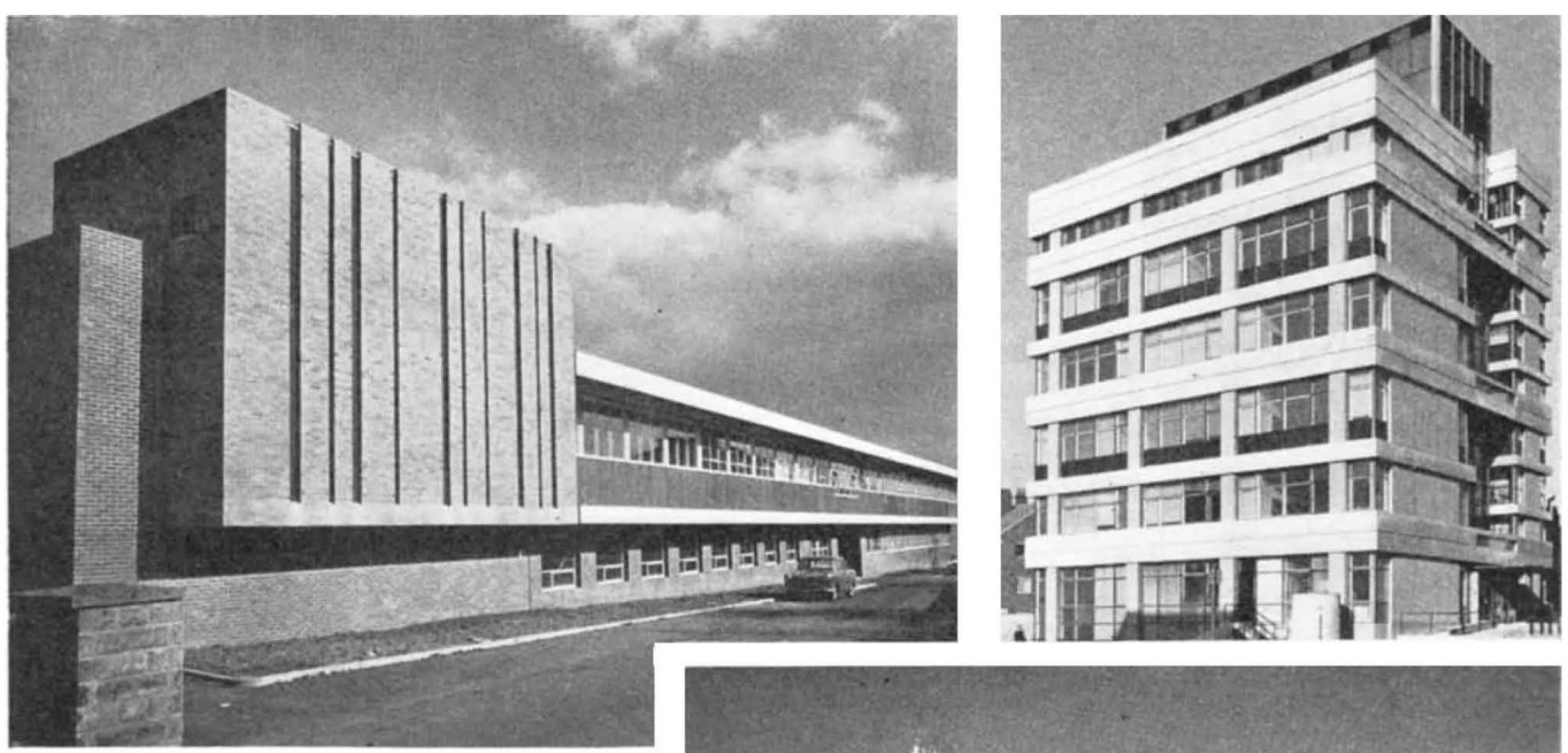

Three university buildings formally opened on May 2 .

Above: Chemistry building, University of Keele, North Staffordshire.

Above, right: Mathematics building, Queen Mary College, London.

Right: Chemistry building, University of Manchester Institute of Science and Technology.

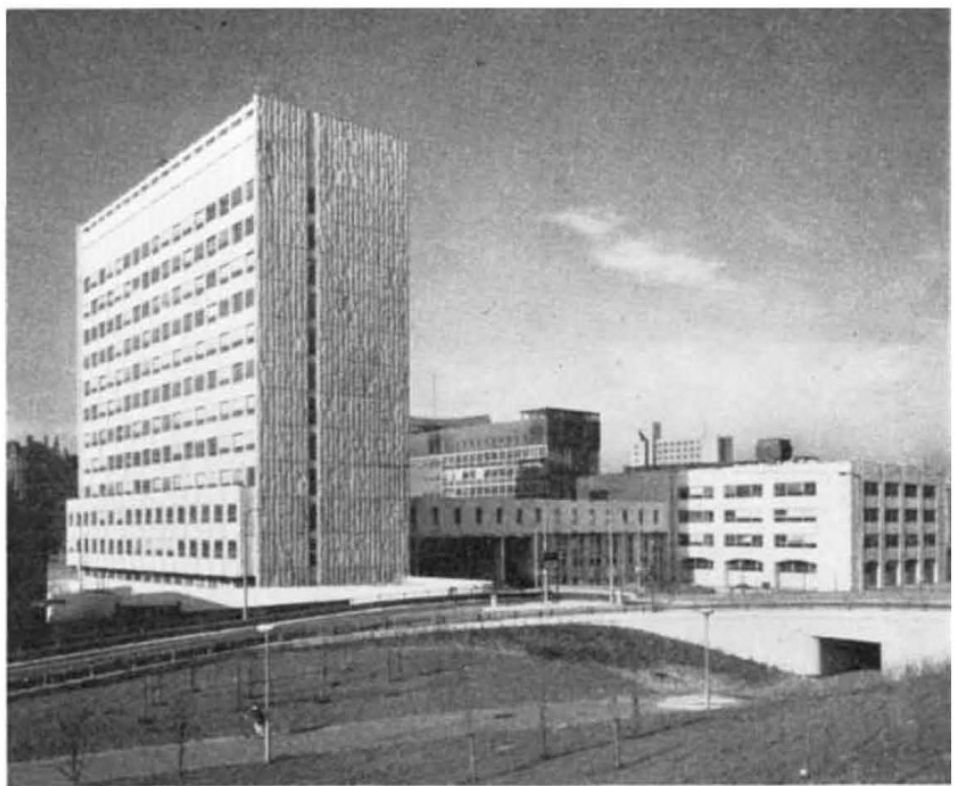

\section{New University Buildings}

THe formal opening of the chemistry building at Keele University by Lord Todd marks the completion of a four-stage building programme that has been spread over 17 years. The department will now accommodate comfortably the chemistry students in a university population of 3,000 , with provision for fifty undergraduates a year. Under a staff of eleven there are more than twenty postgraduate students. The fourth stage of the building, with floor area of 26,000 square feet, cost $£ 182,200$, which includes the cost of alterations, particularly to the entrance hall and lecture theatre, which now seats 150. An additional sum of approximately $£ 52,900$ has been spent on the furniture and fittings. The new accommodation includes a conputer suite, a thermochemistry suite, research laboratories, staff rooms and a cold room, in a threestorey block, and a two-storey block (see photograph) which contains a teaching laboratory, lecture room, library, radiochemistry suite and other rooms for tutorials, seminars and socializing.

The mathematies building at Queen Mary College has been in use since October 1967, but was formally opened this week by Lord Mountbatten. The building cost $£ 285,377$, without furniture and fittings, providing 35,000 square feet of floor space. There are at present 130 undergraduates, seventy of them being first year students, thirty graduates and more than thirty staff. The computer and related equipment occupy the top two levels of the seven-storey elevation facing Mile End Road; the rear of the building is divided into eleven storeys of smaller rooms for offices and tutorials.

The chemistry building at the University of Manchester Institute of Science and Technology, which was opened by the Duke of Edinburgh, provides for 420 undergraduates. There are at present about 170 postgraduate students and postdoctorate follows, and more than fifty academic staff. The building cost an estimated $£ 2$ million, for the four-storey undergraduate teaching block, the fifteen-storey research block and the bridging section and tunnel between them which house offices, library and stores. In all, the floor area is 256,000 square feet. The department offers undergraduate courses in polymer chemistry and colouring matters, as well as honours and ordinary degrees in chemistry. 